\title{
Should Doctors be Sued for Malpractice When they Don't Inform Patients About the Power of Nutrition?
}

\author{
Skip Stein* \\ Chief Operating Officer Whole Foods for Healthy Living, USA \\ *Corresponding author: Skip Stein, Chief Operating Officer Whole Foods for Healthy Living, USA
}

Submission: May 24, 2018; Published: June 06, 2018

\section{Introduction}

You see it in Social Media all the time about new law suits against drug companies for ineffective or debilitating drugs and dangerous/ deadly side effects. Tobacco companies were successfully sued for billion $\$$ for the deadly/toxic products they advertised/promoted as safe. There is now and has been, overwhelming evidence, peer reviewed studies and even internal documents disclosed to prove that processed food companies know the dangers of their products; yet continue to market/sell them to the public. Studies have proven the health and curative benefits of a whole food plant based lifestyle and diet can achieve, yet you never hear that from your doctor. No, in many cased, doctors actually tell patients that food will have no impact on their condition. These statements are based on either lack of information or outright collusion with medical \& pharmaceutical companies who would lose billion\$ if it were common knowledge that simple lifestyle and nutritional approaches to a multitude of chronic illnesses could be remedied far more effectively, with no side effects, with simple nutritional/alternative approaches. Common chronic illnesses like heart disease, diabetes II and most cancers can be fully prevented and often reversed with nutritional treatments coupled with lifestyle changes, at little cost and without the often-deadly side effects. While this will cost the medical industry and pharmaceutical industries billion\$, it will SAVE the American taxpayer Trillion\$ in annual treatment costs, usually paid/subsidized by medical insurance.

Restoring America's Health will not only contribute to healthier vitality/longevity, but also increase productivity in American Companies. Companies spend tens of thousands of dollars every year in subsidizing/paying for 'health insurance' for employees and their families. Much of these outlays would be unnecessary if the workforce was healthy, seldom was sick and had more energy to do their jobs. Productivity would increase and healthcare/ insurance costs would plummet. Yet, even knowing these facts, you seldom, if ever, hear this from your doctor. People have been taught to 'trust their doctors' but in fact, many just cannot be trusted. They are uninformed, never educated or brainwashed by the slick pharmaceutical representatives who offer an 'easy fix' for their patient's chronic illnesses. Health insurance companies and the medical industry have limited the doctor's time with patients and intimidated them into a pharmacological approach instead of considering a nutritional, lower cost, approach to overall health. It is quick and easy to just reach for the prescription pad for a drug that the patient often requests. The doctor had been reduced to a legal drug pusher; not a healer.

Patients are inundated with TV advertisements for quick/easy remedies for their chronic illnesses that usually have debilitating/ dangerous side effects; yet few pay attention to the mandatory and often dire warnings that accompany the advertisements. People want the easy way, the quick fix and the pill/drug for everything; it just doesn't work that way. These commercials have for decades, convinced people that chronic disease is somehow inevitable and 'normal'. It is a LIE and falsehood created to promote, often deadly products. People are designed to be Healthy. Humans are the ultimate self-healing beings with amazing natural curative powers if and only if, they are provided the proper nutrients to optimize the natural immune/healing systems of the body.

Proper nutrition can be much more effective when treating common chronic ailments like high blood pressure, diabetes II and cancer than most drugs, chemicals and radioactive isotopes could ever hope to achieve. No these 'treatments' are presented with few/ no alternatives and patients are rushed into accepting these oftendeadly approaches instead of even being offered alternative, more cost-effective options. This blatant malfeasance on the part of the medical industry must cease as their current approach does not work. Americans are getting sicker, life-spans shortened and aging is now nothing more than an expectation of disease/treatment/ death; not the graceful event that growing older can actually be. You just don't have to be sick. You are designed to be well and healthy. It is a proven fact that humans can and are living health/active lives well into their 100's in many places around the world; and yes, right here in the USA too. You can be Well/Healthy/Alive/Productive today and tomorrow just by simply changing your lifestyle, what you eat and consider nutrition as the key component of health, not the prescription bottle. 
Maybe we should be suing the medical industry and doctors for failing to inform, teach and remediate common chronic diseases with nutritional options when there are facts that prove the current approach has been and is an abject failure. This malfeasance, in the presence of common knowledge and proof that a Whole food plant based lifestyle can and does achieve better health outcomes, at lower cost and no side effects is criminal. The medical industry refuses to accept the facts, doctors ignore the evidence and continue an approach that is not curing anyone but is simply treating you to death [1-3].

\section{References}

1. Skip stein is a polymath health \& wellness lifestyle counselor and corporate productivity consultant focusing on the power of whole food nutrition and the delicious nature of a plant-centric lifestyle.

2. https://www.linkedin.com/pulse/should-doctors-sued-malpracticewhen-dont-inform-patients-skip-stein/

3. http://publishing.wf4hl.com/suing-doctors-for-malpractice.html
Creative Commons Attribution 4.0

International License

For possible submissions Click Here

\section{Submit Article}

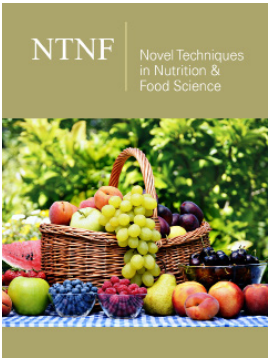

Novel Techniques in Nutrition and Food Science

\section{Benefits of Publishing with us}

- High-level peer review and editorial services

- Freely accessible online immediately upon publication

- Authors retain the copyright to their work

- Licensing it under a Creative Commons license

- Visibility through different online platforms 